[5] Rice, C. D., Espourteille, F. A., and Huggett, R. J., Appl. Organometallic Chem. 6, in press.

[6] Espourteille, F. A., Tributyltin in Oysters, Crassostrea virginica, and Sediments from the Chesapeake Bay, Masters Thesis, School of Marine Science, College of William and Mary, Gloucester Pt., VA (in preparation).

[7] Huggett, R. J., Unger, M. A., and Westbrook, D. J., Organotin Concentrations in the Southern Chesapeake Bay, In: Proceedings of Ocean '86 Organotin Symposium, Marine Technology Society, Washington, DC, 1262-1265 (1986).

\section{Analysis of Gaseous and Particle- Associated PAH and Nitroarenes in Ambient Air}

\section{Janet Arey, Barbara Zielinska, Roger Atkinson, and Arthur M. Winer}

\author{
Statewide Air Pollution Research Center \\ University of California \\ Riverside, CA 92521
}

The organic species present in ambient air vary considerably in volatility and concentration and are distributed between the gaseous and particulate phases. This distribution depends on, among other factors, ambient temperature and the composition of the particulate phase. The major sources of anthropogenic chemicals emitted into the atmosphere are combustion and volatilization, and the more volatile species are often present in high concentrations. This is demonstrated in figure 1 for a series of aromatic hydrocarbons. Literature values for ambient benzene and toluene concentrations [1] and the ambient concentration data we obtained for polycyclic aromatic hydrocarbons (PAH) at Glendora, CA, in August 1986 are shown plotted against their room temperature vapor pressures $[2,3]$. Thus, to measure ambient concentrations of the complete range of PAH and nitroarenes (which are generally at least an order of magnitude less abundant than the parent $\mathrm{PAH}$ ), complementary sampling and analysis techniques are required.

Indicated in table 1 are the sampling technique(s) which provided quantitative concentration valuesfor the listed PAH during 12-h sampling periods. The sampling techniques employed were: sampling at $1 \mathrm{~L} \mathrm{~min}{ }^{-1}$ onto cartridges containing $0.1 \mathrm{~g}$ of Tenax GC solid adsorbent (low-flow Tenax), sampling at $10 \mathrm{~L} \mathrm{~min}$ min $^{-1}$ onto $0.6 \mathrm{~g}$ of Tenax (high-flow Tenax), sampling at 30 SCFM onto four polyurethane foam (PUF) plugs located in series downstream from Teflon-impregnated glass fiber (TIGF) filters in modified high-volume samplers, and standard high-volume sampling at 40 SCFM onto TIGF filters. Crucial to the quantification

Table 1. PAH quantitatively measured and the sampling techniques employed at Glendora, CA, in August 1986

\begin{tabular}{|c|c|c|c|c|c|c|}
\hline m.w. & PAH & $\begin{array}{l}\text { Low- } \\
\text { flow } \\
\text { Tenax }\end{array}$ & $\begin{array}{l}\text { High- } \\
\text { flow } \\
\text { Tenax }\end{array}$ & $\begin{array}{l}\text { PUF } \\
\text { plugs }\end{array}$ & Filter & Comment \\
\hline 128 & Naphthalene & $\mathrm{X}$ & & & & Ave. $2 \%$ on back-up Tenax \\
\hline 142 & 1-Methylnaphthalene & $\mathrm{e} x$ & $\mathrm{X}$ & & & Low- and high-flow Tenax agree \\
\hline 142 & 2-Methylnaphthalene & $\mathrm{e} x$ & $\mathrm{X}$ & & & Low- and high-flow Tenax agree \\
\hline 154 & Biphenyl & & $x$ & & & Too low to quantify on low-flow Tenax \\
\hline 154 & Acenaphthene & & $x$ & & & Too low to quantify on low-flow Tenax \\
\hline 166 & Fluorene & & $\mathbf{X}$ & & & 乏PUFs $\sim 25 \%$ high-flow value \\
\hline 178 & Phenanthrene & & $x$ & $\mathrm{X}$ & & $<10 \%$ on 4 th PUF \\
\hline 178 & Anthracene & & & 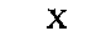 & & Too low to quantify on high-flow Tenax \\
\hline 184 & Dibenzothiophene & & & $\mathrm{x}$ & & \\
\hline 202 & Fluoranthene & & & $\mathbf{X}$ & & $\begin{array}{l}\text { Partially gas-phase } \\
\text { Partially "blown-off" filter } \\
<10 \% \text { on filter }\end{array}$ \\
\hline 202 & Pyrene & & & $X$ & & $\begin{array}{l}\text { Partially gas-phase } \\
\text { Partially "blown-off" filter } \\
<10 \% \text { on filter }\end{array}$ \\
\hline $\begin{array}{l}228 \\
\text { Higher }\end{array}$ & Chrysene/Triphenyle & lene & & $\Sigma Y$ & $\mathrm{X}$ & $20-50 \%$ present on PUFs \\
\hline \multicolumn{3}{|c|}{ Higher Molecular Weight PAH } & \multicolumn{3}{|c|}{$\mathrm{x}$} & \\
\hline
\end{tabular}


procedures was the utilization of a complete range of deuterated internal standards, from naphthalene$\mathrm{d}_{8}$ to dibenz(a,h)anthracene- $\mathrm{d}_{14}$, added to the appropriate samples prior to the extraction step.

Generally the abundant volatile ambient nitroarenes, which include 1- and 2-nitronaphthalene and 3-nitrobiphenyl, are efficiently sampled utilizing PUF plugs [4]. To understand the sources of the nitroarenes observed in ambient air, isomerspecific compound identification is required $[5,6]$. The identification in an ambient particulate extract of the most abundant particle-associated nitroarene species as 2-nitrofluoranthene is illustrated in figure 2. Shown in this figure are the gas chromatographic/mass spectrometric (GC/MS) multiple ion detection (MID) traces for the molecular ion $(\mathrm{m} / z$ 247) of the isomeric nitrofluoranthenes (NF), nitropyrenes (NP) and nitroacephenanthrylenes (NAce) and for the molecular ion $(m / z 256)$ of the corresponding perdeuterated species added as internal standards. The GC/MS identification of 2NF and additional NF, NP and NAce isomers in ambient samples has been achieved through the use of deuterated internal standards in conjunction with the consistent chromatographic resolution and high sensitivity achievable through sample clean-up by high performance liquid chromatographic separations $[7,8]$.

\section{Acknowledgments}

The financial support of the U.S. Environmental Protection Agency, Grant No. R-812973-01 and the California Air Resources Board, Contract No. A5-185-32 is gratefully acknowledged.

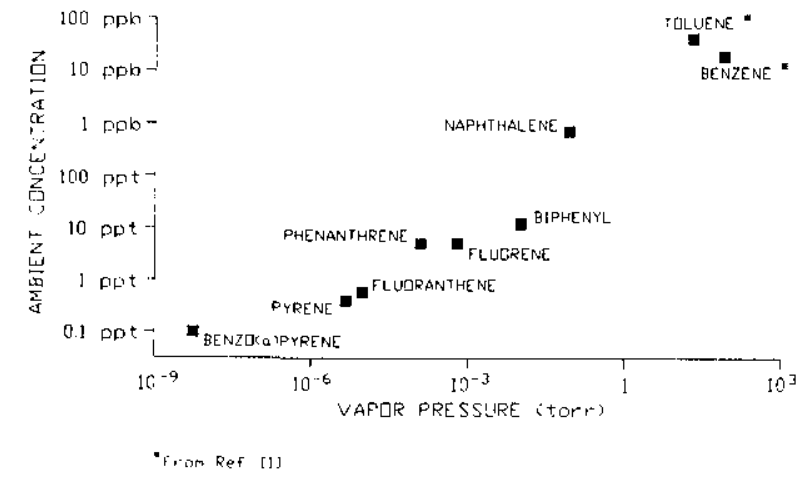

Figure 1. Plot of typical ambient concentrations of a series of aromatic hydrocarbons as a function of their room temperature vapor pressures.

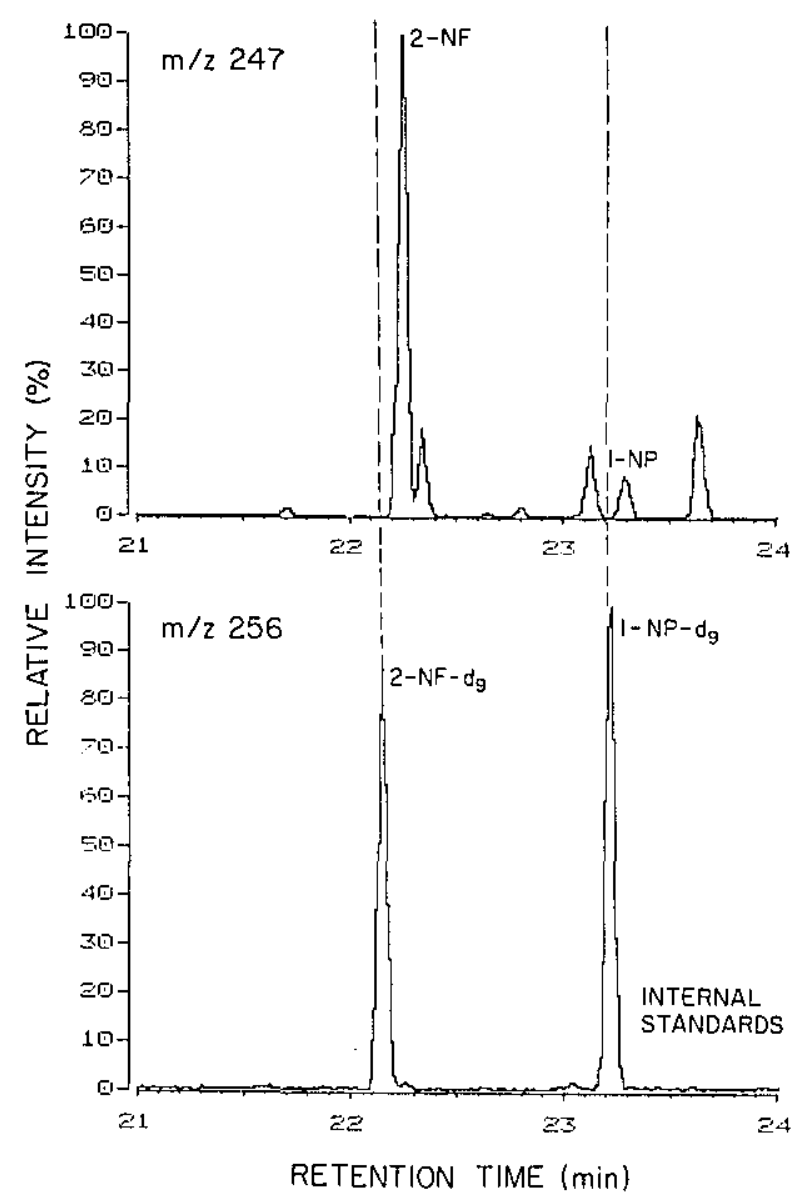

Figure 2. GC/MS MID traces of an ambient particulate sample extract showing that the most abundant NF, NP or NAce isomer is 2-nitrofluoranthene. 


\section{References}

[1] Grosjean, D., and Fung, K., J. Air Pollut. Control Assoc. 34, 537 (1984).

[2] Sonnefeld, W. J., Zoller, W. H., May, w. E., Anal. Chem. 55, 275 (1983).

[3] Yamasaki, H., Kuwata, K., and Kuge, Y., Nippon Kagaku Kaishi 8, 1324 (1984)

[4] Arey, J., Zielinska, B., Atkinson, R., and Winer, A. M., Atmos. Environ. 21, 1437 (1987)

[5] Arey, J., Zielinska, B., Atkinson, R., Winer, A. M., Ramdahl, T., and Pitts, J. N., Jr., Atmos. Environ. 20, 2339 (1986).

[6] Atkinson, R., Arey, J., Zielinska, B., Winer, A. M., and Pitts, J. N., Jr., The Formation of Nitropolycyclic Hydrocarbons and their Contribution to the Mutagenicity of Ambient Air, In: Short-Term Bioassays in the Analysis of Complex Environmental Mixtures V, Sandhu, S. S., DeMarini, D. M., Mass, M. J., Moore, M. M., and Mumford, J. S., Eds., Plenum Press, in press (1987).

[7] Zielinska, B., Arey, J., Atkinson, R., and McElroy, P. A., Nitration of Acephenanthrylene Under Simulated Atmospheric Conditions in Solution, and the Presence of Nitroacephenanthrylene(s) in Ambient Particles, Environ. Sci. Technol., submitted for publication (1987).

[8] Zielinska, B., Arey, J., Atkinson, R., and Winer, A. M., The Nitroarenes of Molecular Weight 247 in Ambient Particulate Samples, J. Chromatogr., to be submitted (1987).

\section{Pattern Recognition Classification and Identification of Trace Organic Pollutants in Ambient Air from Mass Spectra}

\section{Donald R. Scott}

U.S. Environmental Protection Agency

Research Triangle Park, NC 27711

\section{and}

\section{William J. Dunn III and S. L. Emery}

College of Pharmacy

University of Illinois at Chicago

Chicago, IL 60612

\section{Introduction}

The most frequently used method of analysis of trace organic pollutants in ambient air is gas chromatography-mass spectrometry (GC-MS). Presently, target compounds in air monitoring samples are identified from gas chromatographic retention times and a combined forward-reverse search of mass spectral reference spectra. The primary objective of this study is to develop computational pattern recognition procedures for the identification of chemical classes and, if possible, individual compounds from routine GC-MS data files. The additional information on nontarget compounds would supplement compound identifications obtained from the target list. The target set of compounds investigated consisted of 78 substituted benzenes, haloalkanes and haloalkenes.

\section{Methods \\ SIMCA Pattern Recognition}

SIMCA pattern recognition was developed by Wold and coworkers [1] for application to classification problems in chemistry. The technique is based on the modeling of chemical classes by disjoint principal component models. Once the class models have been determined, objects are classified by fitting their data to the class models. A standard deviation for each model is calculated from the residuals which represents a class tolerance level around the model in measurement space.

\section{Data Analysis}

In this study an IBM PC-XT microcomputer with $640 \mathrm{~K}$ memory was used. A modified version of the SIMCA program was used for the majority of the pattern recognition calculations. The low resolution mass spectra of 78 compounds were obtained from the EPA-NIH Mass Spectral Library on an INCOS data system (see table 1). The GCMS data files were from routine calibration and analysis performed by the Environmental Monitoring Systems Laboratory, U.S. Environmental Protection Agency, Research Triangle Park, NC.

The data were preprocessed by taking the autocorrelation transform of the mass spectra for mass lags less than 100 . In the initial stages of class modeling, the autocorrelation transformed spectra for the 78 training compounds were examined for class separation with two and three dimensional principal components projections of the training data. Three different groups were found: nonhalogenated benzenes; chloroaromatics, chloroalkanes, chloroalkenes; and bromocarbons.

Principal components models were then derived for each class [2]. None of the class models 